\title{
Poverty Profiling of the Estuarine Set Bag Net Fishermen Community in Bangladesh
}

\author{
Md. Rashed-Un-Nabi (Corresponding author) \\ Institute of Marine Sciences and Fisheries \\ University of Chittagong, Chittagong, BD 4331 \\ Tel: +88-017-1221-0776_Email: mrnimscu@yahoo.com \\ Md. Azharul Hoque \\ Manitoba Water Stewardship, Box- 19, 200 Saulteaux Crescent \\ Winnipeg, Manitoba, Canada R3J 3W3 \\ Tel: +1-204-945-6477Ｅ-mail: azharulhoq@hotmail.com
}

Ridzwan Abdul Rahman

Borneo Marine Research Institute, University Malaysia Sabah (UMS)

Kota Kinabalu, Sabah 88999, Malaysia

Tel: +6-088-320-000 Extn: 5909, 2643 E-mail: ridzwan@ums.edu.my

Saleem Mustafa

Borneo Marine Research Institute, University Malaysia Sabah (UMS)

Kota Kinabalu, Sabah 88999, Malaysia

Tel: +6-088-320-000 Extn: 2639 E-mail: saleem@ums.edu.my

Md. Abdul Kader

Institute of Marine Sciences and Fisheries

University of Chittagong

Chittagong 4331, Bangladesh

Tel: +88-031-716-552, 716558 Extn: 4311 E-mail: makaderims@yahoo.com

Received: June 19, 2011 Accepted: July 17, $2011 \quad$ doi:10.5430/rwe.v2n2p2

This research was sponsored by Support for University Fisheries Education and Research (SUFER) Project of the University Grants commission of Bangladesh funded by DFID.

\begin{abstract}
Poverty is a major threat to the coastal communities specially the estuarine set-beg net fishermen in Bangladesh. This study covers the poverty profiling of this community through traditional approaches as well as sustainable livelihoods approach. The headcount ratio of the investigated villages ranged between $43 \%$ and $74 \%$ with an average $52 \%$ which is higher then the national poverty level (37.4\%) of Bangladesh. Livelihoods assets profiling shows that high level of poverty is prevailing in all the capital assets needed for the sustainable livelihoods of the estuarine set bag net fishermen. Poverty levels of different livelihood components are quantified using fuzzy method. Human poverty index, physical poverty index, social poverty index, financial poverty index and natural poverty index of the estuarine set bag net
\end{abstract}


fishermen community of Bangladesh are found to be $0.64,0.29,0.66,0.55$ and 0.85 respectively. Natural, social and human poverty levels are found to be very much acute among the five capital assets investigated.

Keywards: Poverty Level, Poverty Line, Multidimensional Approaches, Sustainable Livelihoods Approach, Fuzzy Method.

\section{Introduction}

In Bangladesh around 22\% capture fisheries are contributed from marine fisheries of which 93\% is contributed from the artisanal fisheries and the rest 7\% is contributed from the industrial fisheries (Fisheries Resources Survey System, 2004). The small scale fishing operation is mainly from shoreline to 30m depth (Sahidullah, 1983). Fishing is on daily basis to weekly (weekly only in dry Season). The artisanal fishers use different types of gears, such as gill net, estuarine set bag net, marine set bag net, beach seine, push net etc. to exploit the multi-species mix. According to Mazid (2002), 30\% catch of the coastal small-scale fisheries is contributed by the set bag net fishery while the balance is from the seasonal gears like gill net, seine net, hook and line etc. Among the set bag net fishery, 73\% is contributed by the estuarine set bag net (ESBN) while the rest is from the marine set bag net (MSBN) which is highly seasonal. Around one million people in the coastal area of Bangladesh are fully or partially dependent on the estuarine set bag net fishery in Bangladesh (Sabbir, 2005). With increasing ESBN fishing pressure in the coastal area of Bangladesh, there are increasing interests and concerns among the communities, researchers and policy makers about the vulnerability of ESBN fishermen. There are few literature (Akerman, 1986; Islam et al., 1993; Islam, 1994; Khan et al., 1997) recommending the management on ESBN fisheries. However, these recommendations are yet to be implemented as these may create socio-economical problems within the ESBN fishermen community. Because this recommendation emphasized mainly the existing financial crisis of the community rather than other aspect of poverty such as in terms of human, physical, social and natural capital of the community. Poverty analysis and measurement of a certain community is a fundamental development criterion to (i) know the existing situation, (ii) understand the factors determining this situation, (iii) design interventions best adapted for the existing situation, and (iv) assess the effectiveness of current policies and to determine whether the situation is changing (Coudouel, et al., 2002). The definition of poverty has developed from a focus on low income and consumption, first to cover a lack of basic needs, then to include a need of basic human rights, and finally to signal more qualitative understandings that capture peoples’ own experiences and definitions, including psychological aspects such as feelings of powerlessness, humiliation and insecurity (Narayan et al., 2001; Allison \& Horimans, 2006). When the aggregate income or consumption volume at the household or individual level is available, poverty line (PL) is used as the indicator of well-being to estimate the poverty level of a country from monetary point of view. Poverty line is the cut-off points separating the poor from the non-poor. Different methods have been used in the literatures to define the poverty line (Deaton, 1997; Ravallion \& Bidani, 1994; Ravallion, 1994; Wodon, 1997). However, most of the methods designed for the analysis of poverty have two main limitations: (i) they are unidimensional; refer to only one indicator of poverty, and (ii) they need to dichotomous the population into the poor and the non-poor by means of the so called poverty line (Betti et al., 2005). Nowadays, poverty is recognized as a complex phenomenon and it should not be reduced to the sole monetary dimension (Filippone et al., 2001). This leads to the development of multidimensional approaches that consists of extending the analysis to a variety of non-monetary indicators of living conditions like gross domestic product (GDP) and human dimension index (HDI). Traditionally, gross domestic product (GDP) per capita is the most commonly used indicator to compare wealth among nations and to measure as stock concept which is just a narrow idea of well-being and is simply a single dimension of the poverty (Bérenger \& Verdier-Chouchane, 2006). On the contrast, the human dimension index (HDI) was precisely created in 1990s by the United Nations Development Program (UNDP) to measure broader aspects of development as well as to reflect a new concept of how to achieve development. The HDI was based on the theoretical 'Capability approach' of Sen (1985) which was both qualitative and multidimensional (Sen, 1999).

The sustainable livelihoods approach (SLA) emerging as an alternative poverty-reduction approach just as development agencies were debating the need for new ways of practicing growth to enable countries to move towards the objectives of the millennium development goals (MGD), agreed by 149 countries at the United Nations Millennium Summit in New York, is halving of poverty by 2015 (Frankenberger, 2001). SLA is made up of the best of all the past practices in a participatory approach and configured into a new framework that together hold the promise of enabling more sustainable means of reducing poverty (Chamber \& Conway, 1991).

The PL, GDP (unidimensional) and HDI (multidimensional) are based on the approaches where the voice of the people is not adequately reflected as these approaches have no options for the end users to participate in the index construction. The people only deliberate the information according the need of the analyst and the analyst collect the information according the set format of PL, GDP and HDI. As the SLA uses the participatory approach it can be used to profile the 
poverty level through livelihoods assets identification where the people could deliberate and incorporate their ideas in the analysis process according to their knowledge base and practical need.

Given the limitation of the PL, GDP and HDI approach of poverty level measurement, a multidimensional analytical method has been used to quantify in the present study to measure poverty of the ESBN fishing community of Bangladesh. Chelie and Lemmi (1995) reported that the poverty is a multidimensional reality and used fuzzy sets statistical theories (Zqdeh, 1965) to measure the magnitude and distribution of poverty. The totally fuzzy and relative (TFR) approach proposed by Cheli and Lemmi (1995) proves usefulness in this regard because it allows capturing the multidimensional nature of poverty avoiding the use of arbitrary thresholds imposed from the outside (Pittaluga et al., 2004).

The main aim of this study is to determine the poverty profile of the ESBN communities of Bangladesh by analyzing different components of poverty matrix. At first, a preliminary view of the poverty status is determined by adopting the traditional measures for poverty analysis i.e. poverty line, headcount ratio and the poverty gap. Then the different asset components, as adopted in sustainable livelihoods approach, are evaluated. Finally, overall poverty profiling of the ESBN community is conducted using the totally fuzzy and relative approach following Cheli \& Lemmi (1995).

\section{Materials and Methods}

\subsection{Study Area}

Bangladesh possesses a typical tropical multi-species fisheries ecosystem. The estuarine set bag net (ESBN) fishery is spread throughout the channels, canals, tributaries and estuaries of the country in coastal and brackish water environment. This gear is operated mostly within $10 \mathrm{~m}$ depth line throughout the year. However, the present investigation was carried out in two coastal districts of Bangladesh namely Chittagong and Cox's Bazar as more than $50 \%$ of the ESBN fishing operation takes place in this region (Islam et al., 1993). Two villages from each district were selected, viz. Poschim Kutubdia Para of Charpara and Ghorokhghata Jaladas Para of Moheskhali in Cox's Bazar district while Maddhom Para of South Kattoli and Boro Kumira Jaladas Para of Sitakunda in Chittagong district, for the present study. The villages were selected based on the criteria that the primary occupation of the villagers is related to ESBN fishing. For convenient, in the present study, the villages were termed as Charpara, Moheskhali, Kattoli and Kumira respectively. The location of the villages is shown in Figure 1.

\subsection{Traditional Poverty Measurement}

\subsubsection{Primary Data Collection}

Data was collected from the mentioned four selected villages through household survey for each month from January 2005 to December 2005. Information on the average monthly income of the each household (HH) from their main occupation, additional occupation, loan taken, loan paid and savings during a particular month was collected.

The net income per month was calculated as:

$$
\begin{aligned}
& N I_{i}=\left(I M O_{i}+I A O_{i}+L T_{i}\right)-\left(L P_{i}+M S_{i}\right) \\
& \text { where, } \\
& i=\text { Months }=1,2, \ldots \ldots . .12 \\
& N I_{i}=\text { Net income per month } \\
& I M O_{i}=\text { Income from main occupation } \\
& I A O_{i}=\text { Income from additional occupation } \\
& L T_{i}=\text { Loan taken } \\
& L P_{i}=\text { Loan paid } \\
& M S_{i}=\text { Monthly Savings }
\end{aligned}
$$

The average monthly income was calculated as: $A M_{i}=\frac{1}{12} \sum N I_{i}$

Then per capita income of the HH was calculated as: Per Capita Income $=\frac{\mathrm{AM}_{\mathrm{i}}}{\text { Total HH member }}$ 


\subsubsection{Secondary Data Collection}

Secondary data was collected on the poverty line (PL) of Bangladesh, base year and local money inflation rate from the base year to the data collection year. A household income and expenditure survey (HIES) was conducted in 2000 by the Bangladesh Bureau of Statistics (BBS, 2000; The World Bank, 2002) and these secondary data was used as the baseline information for this present study.

\subsubsection{Treatment of Poverty Line}

According to BBS (2000), the lower poverty line (LPL) per capita per month was BDT549.00 (Bangladesh currency = BDT = Bangladesh Taka) in the year 2000 for the rural area of the Bangladesh. In the present study this amount was treated as the base poverty line. This value was updated for the year 2005 by the local currency inflation rate. According the International Monetary Fund (IMF) this inflation during the year 2005 was 7\% when compared to year 2000. Hence, the rural lower poverty line for the year 2005 would be BDT587.43 and this was treated as the poverty line for the rural area of Bangladesh in the present investigation.

\subsubsection{Data Analysis for Traditional Poverty Measurement}

\section{Head Count Ratio (HCR)}

This is the share of the population that is poor. Specifically, the proportion of the population for which consumption or income is less than the poverty line. Head count ratio was calculated after Klugman (2002):

$H=\frac{Q}{N}$

where

$H=$ Head count ratio

$Q=$ Number of household $(\mathrm{HH})$ below poverty line

$N=$ Population size

Poverty Gap (PG)

The mean distance below the poverty line as a proportion of the poverty line, where the mean is taken over the whole population, counting the non-poor as having zero poverty gaps (Klugman, 2002). It is expressed as

$$
P G=\frac{1}{n} \sum_{i=1}^{Q}\left[\frac{Z-Y_{i}}{Z}\right]
$$

where,

$Y_{i}=$ Income of individual

$i=$ Number of $\mathrm{HH}$ whose income is bellow the poverty line

$Z$ = National poverty line after necessary treatment as stated in 'treatment of poverty line' section.

\subsection{Poverty Profiling through Sustainable Livelihoods Approach (SLA)}

The poverty profiling was conducted through participatory methods following the DFID's sustainable livelihoods approach (SLA) (Chamber \& Conway, 1991) where the livelihoods assets of the fishermen were indexed through semi-structured questionnaires. From each investigated village, 25\% fishing households were selected through stratified random sampling. Household chiefs were chosen as the respondent irrespective to male or female.

Following the SLA framework (Chamber \& Conway, 1991), the questionnaire was divided into five major asset groups where each groups contained several micro-attributes. The five major asset groups are:
i. Human Asset
ii. Physical Asset
iii. Social Asset
iv. Financial Asset
v. Natural Asset 
The probable answers of the micro-attributes were identified and ranked in such a manner where the first answer reflects the lowest poverty and the last answer reflect the highest poverty (Pittaluga et al., 2004).

\subsubsection{Background of Questionnaire Development}

Before preparing the questionnaire, two focus group discussions were conducted in each of the selected villages with the ESBN fishermen (8 to 12 fishermen per group) to find out the scalable attributes (variables) appropriate to measure the poverty according to the SLA guideline (Chamber \& Conway, 1991; Pittaluga et al., 2004). The preliminary micro-attributes were chalked out during the group discussion and then finally one key informant discussion was conducted in each village with representatives of institutions (key informant) at village level. This included village leaders, teachers, religious leaders, and representatives of local welfare groups in the villages. During the key informant discussion, thirty-four single attributes were selected with their possible answers which were ranked according to the ordinal scale. Selection criteria for the questions were -

i. Easily understandable and answerable by the fishermen, and

ii. Carrying great weight from poverty viewpoint (i.e. to index the poverty).

Finally the selected thirty-four micro-attributes were broadly categorized into five assets groups of the SLA approach. Hence, each groups comprised a set of dimensions and such dimensions can be called micro-variables and constitute a series of empirically observable facts (Pittaluga et al., 2004).

\subsubsection{Analytical Approach}

Fuzzy sets, as developed by Zadeh (1965) and expanded by Dubois \& Prade (1980), provide an ideal framework to address the issues of poverty by allowing every individual to some degree of deprivation in each dimension of poverty. Cheli \& Lemmi (1995) proposed a measure of poverty which is totally fuzzy and relative (TFR) with a multidimensional framework (Qizilbash, 2002). In mathematical term the approach can be described as follows.

For each examined variable one defines a function that indicates the degree of membership of each statistical unit to a certain fuzzy subset of the whole population considered (Cerioli \& Zani, 1990; Cheli \& Lemmi, 1995; Lemmi \& Pannuzi, 1995).

In a sample of $J$ households, let $X_{i} \quad(i=1,2, \ldots \ldots . I)$ be a vector of observed characteristics for each household. The fuzzy set of the poor can be defined as:

$$
f\left(x_{i}\right)=\frac{\sum_{j=1}^{j} g\left(x_{i j}\right) \cdot w_{j}}{\sum_{j=1}^{j} w_{j}} \quad(i=1,2, \ldots . . I)
$$

Where $w_{j}$ is the weight attributed to $x_{j}$

Following this definition one obtains:

$0 \leq f\left(x_{i}\right) \leq 1$

In particular,

$f\left(x_{i}\right)=0$, if $x_{i}$ is completely noon-poor in the $j$ attributes

$f\left(x_{i}\right)=1$, if $x_{i}$ is totally poor in the $j$ attributes

$0 \leq f\left(x_{i}\right) \leq 1$ if $x_{i}$ is partially or totally deprived in some attributes but not fully deprived in all of them.

The TFR method adopts the following specification of the deprivation measure according to a generic poverty indicator $X$ (Cheli \& Lemmi, 1995):

$$
g\left(x_{i}\right)=\left\{\begin{array}{lc}
H\left(x_{i}\right) & \text { if the poverty grows as } X \text { increases } \\
1-H\left(x_{i}\right) & \text { otherwise }
\end{array}\right.
$$


where, $H()$ represents the observed distribution function of $x$ and subscript $i$ refers to the $i$-th household. According to the fuzzy sets theory $g\left(x_{i}\right)$ can be interpreted as membership function (m.f.) in the fuzzy subset of the poor calculated for the $i$-th household (Betti et al., 2005).

However, when the $x$ variable is ordinal and the frequency associated to one of the extreme categories is rather high, one should adopt a normalized version of the previous specification given by

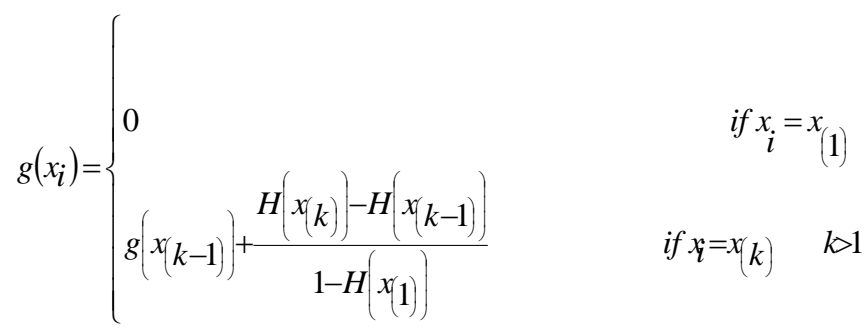

where, $x_{(1)}, \ldots, X_{(m)}$ represent the categories of $x$ sorted in increasing order with respect to the risk of poverty. After simple manipulations, the preceding formula can also be written as follows (Filippone et al., 2001):

$$
g\left(x_{i}\right)=\frac{H\left(x_{(k)}\right)-h\left(x_{1}\right)}{1-h\left(x_{(1)}\right)} \quad \text { for } x_{i}=x_{(k)}, \quad k=1, \ldots . . m
$$

where, function $h()$ associates any category of $X$ to the corresponding relative frequency.

In this way, $g()$ always takes value 0 in correspondence to the lowest category of $X$ (i.e. lowest risk of poverty) and 1 in correspondence to the highest one. In correspondence to the intermediate categories, $g()$ takes values between 0 and 1 that are not influenced by the extreme categories and depend on the empirical distribution of $X$.

In practice, $g\left(x_{i}\right)$ represents an individual index of deprivation specific for item $X$. A collective index specific for $X$ is defined as the arithmetic mean of the $g\left(x_{i}\right)$ memberships in the population:

$$
P=\frac{1}{n} \sum_{i=1}^{n} g\left(x_{i}\right)=\sum_{k=1}^{m} h\left(x_{k}\right) * g\left(x_{k}\right)
$$

The system of weights used is

$w_{j}=\ln \left(1 / \overline{g / x_{j}}\right)$

where, $\overline{g / x_{j}}=\frac{1}{n} \sum_{i=1}^{n} g\left(x_{i j}\right)$ represents the fuzzy proportion of poor households with respect to $X_{j}$.

\section{Results}

\subsection{Traditional Poverty Measurement}

\subsubsection{Average Monthly Income}

The average monthly income of the fishermen household ranged between BDT452.67 and BDT28333.33 with an overall average BDT4756.14 \pm 3845.01 . The highest was observed in the village Charpara while the lowest was observed in the village Kumira. The average monthly income per household was found to be BDT4512 \pm 4581 , BDT2987 \pm 926 , BDT3548 \pm 1725 and BDT5566 \pm 3443 for the villages Charpara, Moheskhali, Kattoli and Kumira respectively (Figure 2a). The per capita income ranged from BDT111.11 to BDT7083.33 with an average of BDT800.18 \pm 727.03 . The average per capita income was found to be BDT709.11 \pm 688.96 , BDT801.98 \pm 489.12 , BDT999.37 \pm 1493.24 and BDT856.57 \pm 571.61 for the villages Charpara, Moheskhali, Kattoli and Kumira respectively (Figure 2b).

\subsubsection{Poverty Line}

According to BBS (2000), the lower poverty line (LPL) per capita per month was BDT549.00 (Bangladesh currency = BDT = Bangladesh Taka) in the year 2000 for the rural area of the Bangladesh. In the present study this amount was 
treated as the base poverty line. This value was updated for the year 2005 by the local currency inflation rate. According the International Monetary Fund (IMF) this inflation during the year 2005 was 7\% when compared to year 2000. Hence, the rural lower poverty line for the year 2005 would be BDT587.43 and this was treated as the poverty line for the rural area of Bangladesh in the present investigation.

\subsubsection{Head Count Ratio}

Per capita income below the poverty line was found maximum (74\%) for the village Moheskhali while the lowest value (43\%) was found for Kumira. For Charpara and Kattoli the head count ratio was found to be $57 \%$ and $55 \%$ respectively (Figure 3). The combined head count ration for all the villages were found to be $52 \%$.

\subsubsection{Poverty Gap}

Poverty Gap values were found greatly varied between different villages. These were $29 \%, 23 \%, 12 \%$ and $12 \%$ for the Charpara, Moheskhali, Kattoli and Kumira villages respectively (Figure 4). The combined poverty gap was found to be $20 \%$.

\subsection{Poverty Profiling through Sustainable Livelihoods Approach (SLA)}

\subsubsection{Human Poverty Index (HPI)}

Human poverty Index consists of following five attributes:
i. Education
ii. Main occupation
iii. Non-earning family members
iv. Monthly HH income
v. Training

Figure 5a shows the individual poverty level in terms of human attributes for different villages while Figure 5b illustrates the combined poverty level of human attributes of four villages' altogether. Combined poverty level for the attribute "Education" was 0.73 with the highest (0.78) in Charpara and the lowest (0.66) in Kattoli. A wide difference can be observed for the attribute "Main occupation" where the highest poverty level (0.78) in Kumira and the lowest $(0.45)$ in the village Charpara with a combined value of 0.55 . For the attribute "Non-earning family member" a very few fluctuation was found in the poverty level between the investigated villages with a combined poverty level of 0.61 . For the attribute "Monthly HH income" a relatively low fluctuation was found between the studied villages with a combined value of 0.69 . The attribute "Training" showed a wide fluctuation of poverty level between the studied villages having a combined value of 0.70 .

\subsubsection{Physical Poverty Index (PPI)}

The physical poverty indexes were determined based on the following ten attributes:

i. Boat ownership

ii. Number of boat per $\mathrm{HH}$

iii. Net ownership

iv. Total number of net per $\mathrm{HH}$

v. HH land ownership pattern

vi. Fishing area ownership pattern

vii. HH holding categories

viii. Drinking water facilities

ix. Sanitation system

x. Power supply

Individual poverty level for each physical attribute for different villages is shown in Figure 6a. Figure $6 \mathrm{~b}$ illustrates the combined poverty level of physical attributes of four villages' altogether. Poverty index for the variable "Boat ownership" ranged between 0.50 and 0.89 with a combined poverty level of 0.57 . Combined poverty level for the attribute "Number of boat per HH" was 0.67 , where, the highest value (0.84) was in Moheskhali and the lowest $(0.53)$ was in Kumira. A wide range, between 0.36 and 0.82, was observed for the attribute "Have net" with the combined 
value of 0.46 . Poverty level for the attribute "Total number of net per HH" ranged between 0.40 and 0.94 . The attribute "HH categories" ranged between 0.42 and 0.85 with a combined effect of 0.47 . The attributes "HH land ownership pattern", "Drinking water facilities", "Sanitation system" and "Power supply" showed low combined poverty level where the values were found to be $0.18,0.13,0.14$ and 0.25 respectively. However, for the attribute "HH holding categories" the combined poverty level was 0.46 where the highest poverty level $(0.85)$ was in Charpara and the lowest poverty level (0.42) was in Kumira.

\subsubsection{Social Poverty Index (SPI)}

In Social Poverty Index, the following eight attributes were included:
i. Neighbor relationship
ii. Neighbor cooperation in vulnerability
iii. Local government support
iv. Medical facilities
v. Support from law enforcement authority
vi. Educational and training facilities supported by NGO
vii. Social conflict
viii. Boat and net security

Figure 7a shows the individual poverty level for each social attributes for different villages while Figure 7b illustrates the combined poverty level of social attributes of four villages' altogether.

The attribute "Neighbor relationship" showed relatively low poverty value (0.37) when compared to all other attributes selected for social poverty indexing. However, Moheskhali showed the lowest value (0.29) of poverty level for neighbor relationship when compared to other villages. The attribute "Neighbor cooperation in vulnerability" also showed the same trend. This is because these two attributes are very much complementary to each other. The combined poverty level of the attribute "Neighbor cooperation in vulnerability" was 0.65 which indicates higher level of poverty for this attribute. The poverty value for the attribute "Local government support" was found lower for the village Charpara when compared to other villages with a combined poverty level of 0.76 . The attribute "Medical facilities" showed highest combined poverty level among the attributes of social poverty index where the individual poverty levels were found to be 0.95, 0.89, 0.84 and 0.89 in Charpara, Moheskhali, Kattoli and Kumira respectively. The individual poverty levels for the attribute "Law enforcement authority help" were found to be 0.81, 0.97, 0.96 and 0.94 in Charpara, Moheskhali, Kattoli and Kumira respectively with a combined poverty value of 0.87 . The combined poverty level of the attribute "Educational and training facilities supported by NGO" was found to be 0.83 with individual values $0.95,0.76,0.94$ and 0.93 for the village Charpara, Moheskhali, Kattoli and Kumira respectively. A relatively low poverty level (0.68) was observed for the village Charpara when the attribute "Social conflict" was compared with other villages noted to be 0.81 , 0.76 and 0.83 for the village Moheskhali, Kattoli and Kumira with a combined poverty level of 0.75 . The attribute "Security for boats and nets" observed a combined poverty level of 0.87 where the individual poverty values were found to be $0.84,0.97,0.97$ and 0.86 for the village Charpara, Moheskhali, Kattoli and Kumira respectively.

\subsubsection{Financial Poverty Index (FPI)}

In FPI six attributes were studied and these were
i. Average monthly income
ii. Saving money
iii. Access to financial institutes
iv. Credit facilities
v. Source of credits
vi. Value/cost of the HH land

Figure 8a shows the individual poverty level for each financial attributes for different villages while Figure 8b illustrates the combined poverty level of financial attributes of four villages altogether.

The value of poverty level for the attribute "Average monthly income" ranged among studied villages between 0.49 and 0.91 with a combined poverty value for all villages was 0.53 . The combined poverty value of the attribute "Save money" was found to be 0.41 where the highest poverty value $(0.74)$ was observed for the Charpara while the lowest 
(0.34) was found for the Moheskhali. For the attribute "Access to financial institute" almost equal poverty values were observed in Charpara, Moheskhali and Kumira (ranged between 0.90 and 0.95) while relatively lower (0.61) level was observed for the Kattoli when this attribute was compared within the four villages. Charpara was found in the highest poverty level (0.98) for the attribute "Credit facilities" while for Moheskhali, Kattoli and Kumira village poverty levels for this attribute were found to be $0.56,0.90$ and 0.80 respectively with a combined poverty value 0.66 . Combined poverty level for the attribute "Source of credits" was found to be 0.69 with highest poverty value (0.74) for the Charpara and lowest (0.62) for the Kattoli. Very low poverty levels were observed for the attribute "Value of HH Land" for the villages Kattoli and Kumira though for the village Charpara this value was found to be 0.73 . The combined poverty level for this attribute was also found very low (0.09).

\subsubsection{Natural Poverty Index (NPI)}

In NPI five attributes were investigated and these were
i. Availability of natural resources
ii. Biodiversity status
iii. Variation in species composition
iv. Trend in total catch
v. Species composition affecting the livelihood

Figure 9a shows the individual poverty level for each natural attributes for different villages while Figure 9b illustrates the combined poverty level of natural attributes of four villages altogether.

Combined poverty level for the attribute "Availability of natural resources" was found to be 0.91 with the highest (0.97) in Kumira while the lowest (0.87) in Kattoli. The highest poverty level (0.95) for the attribute "Biodiversity status" observed for the village Kattoli and the lowest (0.82) was for the village Moheskhali with a combined value of 0.88. For the attribute "Variation in the species composition" the combined poverty level was found to be 0.79 with a range between 0.74 (Charpara) and 0.91 (Kattoli). For the attribute "Trend in total catch" a relatively low fluctuation of poverty values were observed between the studied villages with a combined value of 0.88 . The attribute "Species composition affecting the livelihood" also showed a smaller fluctuation in poverty level between the villages with a combined value of 0.85 .

\subsubsection{Asset-wise Combined Poverty Level}

Figure 10 showed that poverty was prevailing in all the five major asset types as suggested by the SLA and ranged between 0.29 and 0.85 . However, the present study shows that the lowest poverty level was for the physical poverty index $(0.29)$ while the highest level was for the natural poverty index $(0.85)$ followed by the social poverty index $(0.66)$.

\section{Discussion}

\subsection{Traditional Poverty Measurement}

\subsubsection{Average Monthly Income}

A wide variation was observed in the average monthly income of the fishermen in the investigated villages of the present study which was due to different types of occupation related to fishery. Khatun et al., (2004) also reported that the people engaged in the fish related trades earn more than the people engaged as fishing labor or fishermen.

The village Moheskhali was situated in the Moheskhali Island and the fishermen of this village face various difficulties to market their fish due to limited transport facilities. As a result the fishermen of this village do not get the appropriate price against their catch. This is one of the main reasons for the low income per household in Moheskhali village. Low household income due to transport facilities or due to the distance in the landing center and nearby market is a very common phenomenon in case of small scale fisheries (Ali, 1991).

In Kumira about $74 \%$ of the villagers were engaged directly with the fishing which was highest among the investigated villages and this caused relatively high monthly income per household when compared with other investigated villages.

\subsubsection{Poverty Line}

The household income and expenditure survey (HIES) conducted by the Bangladesh Bureau of Statistics (BBS, 2000) suggested that the upper and lower poverty line for the rural area of Bangladesh should be BDT628.00 and BDT549.00 respectively. The difference in poverty line was due to the expenditure for the non-food item per $\mathrm{HH}$. After the adjustment for the national money inflation rate this lower poverty line for the rural area of Bangladesh in the year 2005 was calculated to be BDT 587.43. In the present study about 52\% households of the investigated villages were found 
below the poverty line of the year 2005 which indicated a higher number of people in the investigated villages are still poor when compared with national level (37.4\%) (BBS, 2000).

\subsubsection{Head Count Ratio (HCR)}

This is the share of the population whose income or consumption is below the poverty line, that is, the share of the population that cannot afford to buy a basic basket of goods (Ravallion, 1994; Deaton, 1997; Klugman, 2002). According to BBS (2000), the national headcount ratio for the rural area of Bangladesh is $37.4 \%$ when compared with the lower poverty line. In the present investigation the headcount ratio for all the villages were found above the national HCR. Among the four investigated villages Moheskhali scored the highest HCR (74\%) which is due to its geographical position as stated earlier. However the village Charpara also suffers serious poverty level (HCR 57\%). This is due to the higher level of variation in their occupational type. Almost $42 \%$ population of this village is engaged as shrimp post-larvae (shrimp fry collection) collector whose income is very low when compared to other fish related activities (Paul et al., 1993). For the village Kattoli a considerable number of people (27.30\%) was engaged as fish labor which also reduced the per capita income for this village. The village Kumira scored the minimum deviation with the national HCR. Though the deviation was $-5.6 \%$ which also indicate that this village is also below the national poverty line. However, as $74.0 \%$ of the villagers of Kumira were engaged as fishermen and this village had a relatively better transport facility which caused this village to remain in the better position when compared with the other investigated villages.

\subsubsection{Poverty Gap (PG)}

Poverty gap represents the depth of the poverty. This provides information regarding the distance of the households from the poverty line. This measure captures the mean aggregate income or consumption shortfall relative to the poverty line across the whole population. For Bangladesh, The national poverty gap for the lower poverty line is $8.2 \%$ (The World Bank, 2002). The poverty gaps in the present investigated villages were found higher than the national poverty gap. For the villages of Kattoli and Kumira the lowest poverty gap (12\%) was observed because their per capita income was highest among the investigated villages. On the other side, the depth of poverty was highest for the village Moheskhali as their per capita income was relatively low when compared to other investigated villages.

\subsection{Poverty Profiling through Sustainable Livelihoods Approach (SLA)}

\subsubsection{Human Poverty Index (HPI)}

A high level of deprivation (0.64) was observed for the human poverty measurement attributes. Among the selected five attributes, "Education" was found to be highest followed by "Training" and "Monthly per capita income". "Education and training" is one of the basic needs for the human resource development and this study clearly depicts that the studied communities are highly deprived of these two issues. Almost similar poverty level was recorded for "Non-earning family member" that expresses the passive attitude regarding the family planning program which is one of the major human development indicators in Bangladesh. Classification in the occupational structure can also depict the level of poverty. In Charpara, Moheskhali and Kattoli villages around 27\% to 39\% people were engaged as fishing labor. This is due to the financial inability of them to possess a boat for fishing. "Occupation" as fish trader is found to be a lucrative within the fish related profession. In Charpara, Moheskhali and Kattoli a notable amount of people were also engaged in this occupation (18\% to $26 \%$ ). However, fish trading is almost absent in the village of Kumira. Hence, in spite of having the maximum percentage of fishermen (74\%), the village Kumira faced highest level of poverty in this attribute (Occupation).

\subsubsection{Physical Poverty Index (PPI)}

A very fluctuating physical poverty values were found when physical poverty measurement attributes were taken into consideration. During the analysis total ten individual attributes were selected through the participatory discussion with the fishermen of which the first seven attributes were directly related with the personal property of household. These are "Have boat, "Number of boat”, "Have net”, "Number of net”, "Household land ownership pattern”, "Fishing area ownership pattern", and "Holding category". The rest three attributes "Drinking water facilities", Sanitation system" and "Power supply" is related with the local institutes (like local GO and NGOs). Among the first group "Number of boat" scored highest (0.67) followed by "Have boat" (0.57). The latter two attributes "'Have net" and "Number of net" scored the similar poverty value (0.46). In fact the main apparatus for fishing in the sea is the boat and net, and the fishermen's livelihoods of the investigated villages highly suffer due to lack of these. Though the poverty values of the boat and net related attributes varied between the villages, relatively higher values were observed for the Charpara and Moheskhali villages when compared to Kattoli and Kumira. This indicated that the fishermen of the Chittagong district is little bit better-off then the fishermen of Cox's Bazar district in case of the attributes related to boats and nets. 
About $73 \%$ to $86 \%$ of the households used to live in their own land and for this reason the deprivation level for the attribute "HH land ownership pattern" was found relatively low. In Charpara district 95\% of the household did not possess any personal fishing area. This was due to higher number of fishing labor working in this village were unable to acquire a fishing area in the sea, reflecting the inequity of the occupational structure. For Charpara the attribute "Holding categories" attained higher poverty value when compared with other three villages. In Charpara about 91\% of the household used to live in the thatched house while in other three villages this ranged between $21 \%$ and $27 \%$. Notably lower poverty values were observed for the attributes which were dependent to the GO and NGOs partially. These were "Drinking water facilities", "Sanitation system" and "Power supply" scored 0.13, 0.14 and 0.25 with an exception in Charpara for power supply (0.95). More interestingly, it was observed that the individual poverty value of the village Kattoli was relatively low for these three attributes in comparison to other villages. The main reason for this was the very short distance of the village with the Chittagong city and virtually Kattoli was availing almost all the urban facilities to some extent.

\subsubsection{Social Poverty Index (SPI)}

Poverty values for the attributes "Neighbour relationship" and "Neighbour cooperation during vulnerability" were found lowest for the village Moheskhali when compared to other three villages. The main reason behind this strong social bonding was the location of this village. Moheskhali village is in an isolated island of Bangladesh and the villagers still do not become very much self-centered when dealing with their neighbour for social interactions. However, a relatively good relationship was observed within the neighbours as the poverty value of the attribute "Neighbour relationship" was relatively low in all the investigated villages when compared with the other attributes selected for social poverty index. Very high poverty values for the attributes "Local Union Parishad help”, "Local health center help", "Local NGOs help for education and training" and "Security for boats and nets" reflected high-level of deprivation of the fishermen regarding these public facilities from the government sector.

\subsubsection{Financial Poverty Index (FPI)}

A relatively low poverty level was observed for the attribute "Average monthly per capita income" for the village Kumira when per capita income was compared with other villages. This is due to occupational classification within the fish related activity. Though very few fish traders were observed (3.30\%) in the village of Kumira, there were no PL collector and fishing labor was also low (6.70\%). As the occupation "Fishing" took place in the middle of the ordinal scale of the probable answers, set by the fishermen through participatory discussion, this caused the low poverty level for monthly income in Kumira when compared with other investigated villages. Except for the Charpara village, the attribute "Save money" showed low level of poverty value in the other investigated villages. From the focus group discussion it was informed that the people of the Hindu religion have a greater tendency to save money than the people of the Muslim religion. While the fishermen sound equally for saving their money to the NGOs working in their locality, they prefer public banks to save their money. However, as they face different types of complexity for saving money in the banks they become almost bound to save their money to the NGOs. The poverty value of the attributes "Borrow money" was found higher than the "Save money" which also reflects their severity of poverty. About $80 \%$ to $98 \%$ of the fishermen from the villages of Charpara, Kattoli and Kumira borrow money for their livelihood. A very different scenario was observed when the attribute "Source of Borrow" was taken into consideration. More than $75 \%$ of the fishermen borrow money from the money lenders though they prefer to borrow money from the bank first. This may be considered as the public banks become unsuccessful to provide sufficient facilities for giving loan in a very easy way as the money lenders can. The attribute "Value of HH land" showed very low level of poverty and it may be considered that the fishermen of the investigated villages are not deprived when considering their living place.

\subsubsection{Natural poverty Index (NPI)}

The poverty values for the attribute "Available natural resources" ranged between 0.87 and 0.97 which indicate that the ESBN fishing community is highly deprived from the natural resources. In the group discussion about $86 \%$ to $97 \%$ of the villagers answered that they are solely dependent on the small-scale fisheries due to the scarcity of any other types of natural resources to sustain their livelihood. This is the main reason of their poverty and this micro-attribute scored highest (0.91) among the all other micro-attributes selected in different asset groups. The attribute "Biodiversity" also showed a high poverty level in all the investigated villages. According to the group discussion more than $80 \%$ of the respondent replied that the biodiversity of the ESBN fishery is rapidly decreasing. Variation in the species composition of small scale fisheries is very common all over the world. The ESBN fishery of Bangladesh is not an exceptional to this. For this reason there is no target fish species. One single haul of the ESBN catches around more than 50 species. This is one of the main causes of the high poverty value of the attribute "Variation in the species composition" which scored 0.79 for studied villages. During the group discussion about $82 \%$ to $95 \%$ of the fishermen responded that the total catch 
of the ESBN fishery is decreasing very rapidly. The combined poverty level of attribute "Species composition affecting the livelihood" scored 0.85 which point toward that if the fishermen can catch any target fish species from the ESBN fishery than their livelihood may be more secured than the present situation.

\subsubsection{Asset-wise Combined Poverty Level}

The present study showed that high level of poverty was prevailing in all the capital assets investigated according the SLA format and the poverty values ranged between 0.29 and 0.85 . However, the value for the combined physical poverty was observed lower when compared with other capital poverty indexes. In physical poverty there were two types of attributes. The attributes which were associated with the personal belongings of the household scored high level of poverty value rather than the poverty values of the attributes associated with the government or NGOs part.

For financial poverty index the value was found to be 0.55 . If this value is compared with the monetary poverty i.e. the headcount ratio, 52\% people were found below the poverty line which indicates almost unanimous result for both the methods.

The human poverty Index scored a very high value (0.64) and it indicates that the fishermen are more deprived in the human capital rather than the physical and financial capital. It is very important to mention here that the physical capital and the financial capital of a certain area or a nation is almost fixed, however, there is an opportunity for the development of the human resources and when well-off human resource will be available there will be at least some efforts from the community to increase the financial assets. So, special attention should be initiated for the human resource development for the ESBN fishermen community.

The social poverty Index was also found higher than the physical, financial and human poverty level and the micro-attributes, which, were in some extent related with the involvement of the government, showed very high poverty value. Hence, the government should come forward to provide the necessary support to enhance the social security to the fishermen and as a resultant the social poverty value will be reduced.

The highest poverty level was observed for the natural poverty index and this reflected the extent of dependences of the ESBN fishermen on the natural resources for their livelihood. The fishermen solely depend on the capture fishery which is small-scale and naturally controlled. Due to indiscriminate fishing this resource is also about to be wiped out. Another problem is that the fishermen cannot target any specific fishery due to the multi-species catching nature of the ESBN. Hence, the fishermen need to explore some alternate livelihoods which could be controlled by themselves rather than control by the nature.

\section{Conclusion}

This study covered the poverty profiling of ESBN fisherman community of Bangladesh through quantification of multidimensional poverty indexes rather than measuring only the monetary terms. From the present study it is also clear that the ESBN fishermen of Bangladesh are facing serious poverty from different aspects like human, physical, social, financial and natural assets. Among the five types of asset, natural, social and human poverty have been found very much acute from this study and needs to be considered to a greater extent during the development of the management recommendation and management plan for the estuarine set bag net fishery of Bangladesh.

\section{References}

Akerman, S. E. (1986). The Coastal Set Bagnet Fishery of Bangladesh - Fishing Trials and Investigations. Report No. 34, Bay of Bengal Program, Madras, India.

Ali, M.A. (1991). An investment on some socio-economic and technical problems in pond fish culture in two districts of Bangladesh. Bangladesh J. Aquaculture, 8(1): 47-51.

Allison, E.H. \& Horemans, B. (2006). Putting the Principles of the Sustainable Livelihoods Approach into Fisheries Development Policy and Practice. Marine Policy, 30,757-766.

BBS(Bangladesh Bureau of Statistics). (2000). Statistical Yearbook of Bangladesh. Bangladesh Bureau of Statistics, Ministry of Planning, Government of Bangladesh.

Bérenger, V. \& Verdier-Chouchane, A. (2006). Are African Countries Richer than they are Developed? A Multidimensional Analysis of Well-Being. Economic Research Working Paper No. 83, Tunisia: African Development Bank. 
Betti, G., Cheli, B., Lemmi, A. \& Verma, V. (2005). The Fuzzy Approach to Multidimensional Poverty: The Case of Italy in the 90's. Paper Presented to the Conference on the Measurement of Multidimensional Poverty, Theory and Evidence, August 29-31 2005, The Poverty Center of United Nations Development Program, Brazil.

Cerioli, A. \& Zani, S. (1990). A Fuzzy Approach to the Measurement of Poverty. In: Dagum C. \& Zenga M. (eds.). Income and Wealth Distribution, Inequality and Poverty. Berlin, Germany: Springer Verlag.

Chambers, R. \& Conway, G. (1991). Sustainable Rural Livelihoods: Practical Concepts for the 21st Century. Discussion Paper No. 296, Institute of Development Studies, University of Sussex, Brighton, UK.

Cheli B. \& Lemmi, A. (1995). A Totally Fuzzy and Relative Approaches to the Multidimensional Analysis of Poverty. Economic Notes, 24(1),115-134.

Coudouel, A., Hentschel, S. J. \& Wodon, T. Q. (2002). Poverty Measurement and Analysis. In: J. Klugman, (ed.), A Sourcebook for Poverty Reduction Strategies; Volume 1: Core Techniques and Cross-Cutting Issues, The World Bank, Washington, USA.

Deaton, A. (1997). The Analysis of Household Surveys: A Micro-econometric Approach to Development Policy. Baltimore: Johns Hopkins University Press.

Dubois, D. \& Prade, H. (1980). Fuzzy Sets and Systems. Boston, USA: Academic Press.

Filippone, A., Cheli, B. \& D'agostino, A. (2001). Addressing the Interpretation and the Aggregation Problems in Totally Fuzzy and Relative Poverty Measures. Working Paper No. 2001-22, The Institute for Social and Economic Research, University of Essex, Colchester, UK.

Fisheries Resources Survey System. (2004). Fishery Statistical Year book of Bangladesh. Department of Fisheries, Bangladesh. 47pp.

Frankenberger, T. R. (2001). A Brief Overview of Sustainable Livelihoods Approaches. In: Anonymous (ed.), Proceedings of the Inter-Agency Forum on Operationalizing Participatory Ways of Applying Sustainable Livelihoods Approaches, 7 - 11 March, Sustainable Livelihood Approach Forum, Pontignano (Siena), Italy: Food and Agriculture Organization of the United Nations.

Islam, M. S. (1994). Socioeconomic Status of Marine Fishermen and Their Upliftment. In: Sinha, V. R. P., Mazid, M. A. \& Kamal, M. (eds.). Proceedings of the workshop on Sustainable Development of Marine Fisheries Resources in Bangladesh, 29 August, Cox’s Bazar, Bangladesh: Fisheries Resource Institute.

Islam, M. S., Khan, M. G., Quayum, S. A., Sada, M. N. \& Chowdhury, Z. A. (1993). The Estuarine Set Bag Net Fishery. In: Studies of Interactive Marine Fisheries of Bangladesh, Working Paper no. 89, Bay of Bengal Program, Madras, India.

Khan, M. G., Alamgir, M. \& Sada, M. N. U. (1997). The Coastal Fisheries of Bangladesh. In: Silvester, G. \& Pauly, D. (eds.). Status and Management of Tropical Coastal Fisheries of Asia, Conference Proceedings No. 56, Manila, Philippines: International Center for Living Aquatic Resource Management.

Khatun, F. A., Rahman, M. \& Bhattacharya, D. (2004). Fisheries Subsidies and Marine Resource Management: Lessons from Bangladesh. Research Report, Economics and Trade Branch, United Nations Environment Program, Geneva, Switzerland.

Laderchi, C. R., Saith, R. \& Stewart, F. (2003). Does It Matter that We Do Not Agree on the Definition of Poverty? A Comparison of Four Approaches. Development Studies, 31 (3):243 - 274.

Lemmi, A. \& Pannuzi, N. (1995). Health and Poverty: Longitudinal Models and Empirical Evidences for Developed Countries. Beijing, China: International Union for Social Science and Policy.

Mazid, M. A. (2002). Development of Fisheries in Bangladesh: Plans and Strategies for Income Generation and Poverty Alleviation. Dhaka, Bangladesh: Mazid Publishers.

Narayan, D., Chambers, R., Shah, M. K. \& Petersch, P. (2001). Voices of the poor: Crying out for change. Oxford: Oxford University Press.

Paul, S. C., Mustafa, M. G., Chowdhury, Z. A. \& Khan, M. G. (1993). Shrimp Fry Collection. In: Studies of Interactive Marine Fisheries of Bangladesh, Working Paper no. 89, Bay of Bengal Program, Madras, India.

Pittaluga, F., Salvati, N. \& Seghieri, C. (2004). Livelihood Systems' Profiling; Mixed Methods for the Analysis of Poverty and Vulnerability. Support unit for International Fisheries and Aquatic Research (SIFER), Food and Agriculture Organization of the United Nations, Rome, Italy. 
Qizilbash, M. (2002). A Note on the Measurement of Poverty and Vulnerability in the South African Context. J. Int. Dev. 14:757-772.

Ravallion, M. \& Bidani, B. (1994). How Robust Is a Poverty Profile? The World Bank Economic Review, 8(1),75-102.

Ravallion, M. (1994). Poverty Comparisons. Switzerland: Harwood Academic Publishers. http://dx.doi.org/10.1093/wber/8.1.75

Sabbir, A. (2005). Prospect and Utilization of Low Value and Trash Fish in Bangladesh. Paper Presented at the Regional Workshop on 'Low Value and Trash Fish in Asia-Pacific Region', Hanoi, Vietnam, 7-9 Jun 2005.

Sahidullah, M. (1983). Survey Report of the Fishery Resources of Bay of Bengal by Survey Research Vessels. Fisheries Bulletin No. 1, Marine Fisheries Department, Chittagong, Bangladesh.

Sen, A. (1985). Commodities and Capabilities. Amsterdam: North Holland: Elsevier Science.

Sen, A. (1999). Development as Freedom. Oxford, UK, Oxford University Press.

The World Bank. (2002). Bangladesh: Progress in Poverty Reduction. Background Paper, Presented in Bangladesh Development Forum, Paris, March 13-16, 2002.

Zadeh, L. A. (1965). Fuzzy Sets. Information and Control, 8:338-353.

http://dx.doi.org/10.1016/S0019-9958(65)90241-X

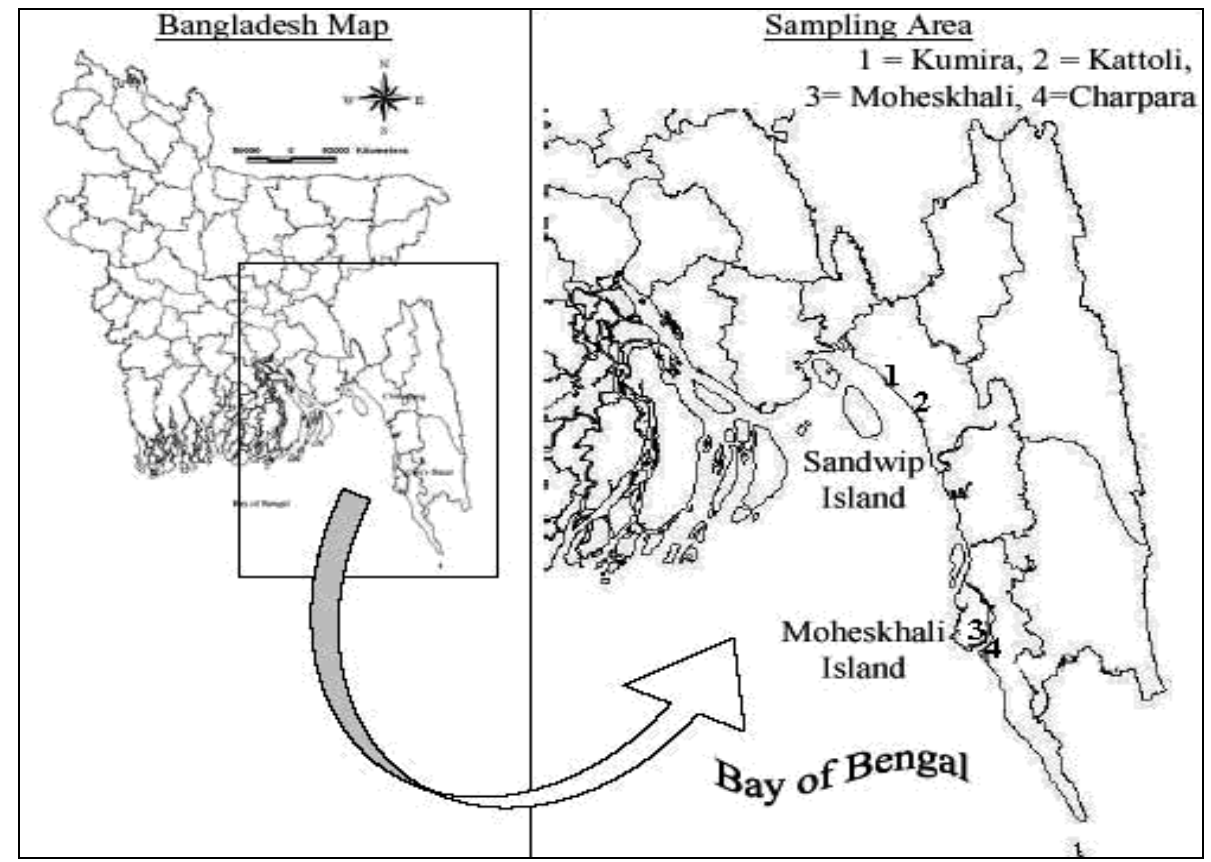

Figure 1. Location of the study area. 


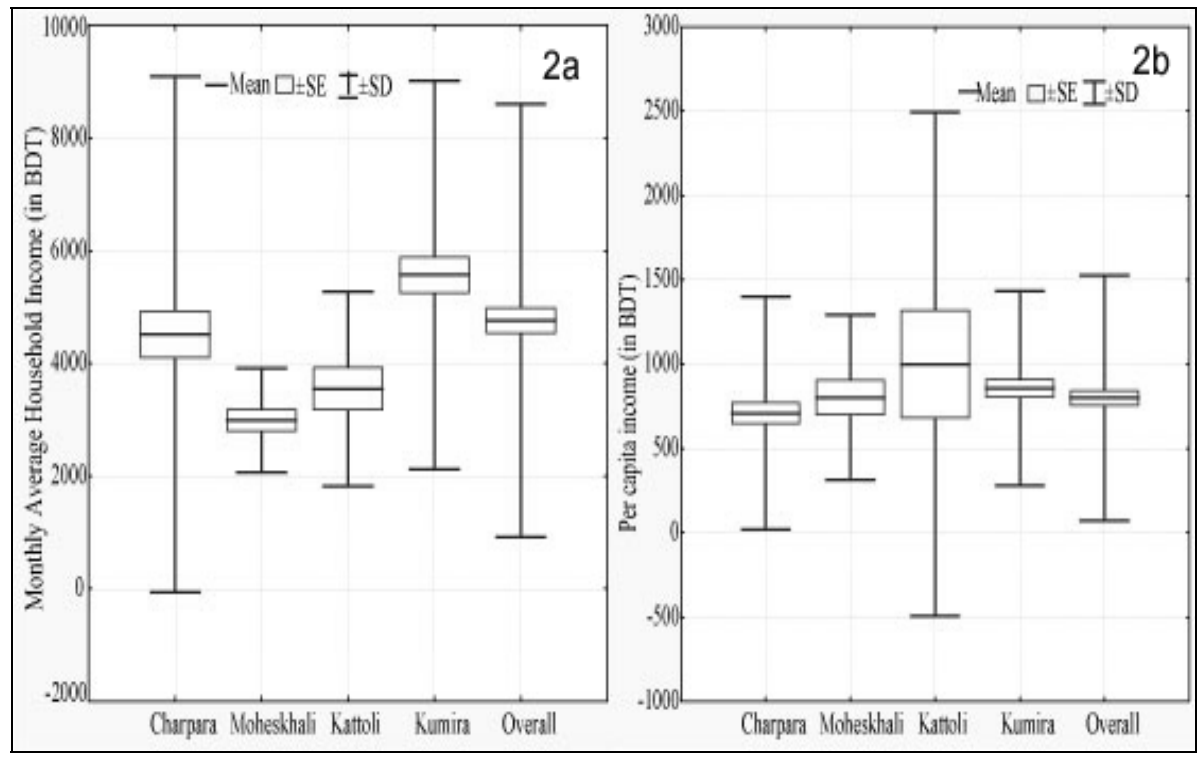

Figure 2. Figure 2(a) showing the average monthly income per household in the four investigated villages while 2(b) showing the per capita income.

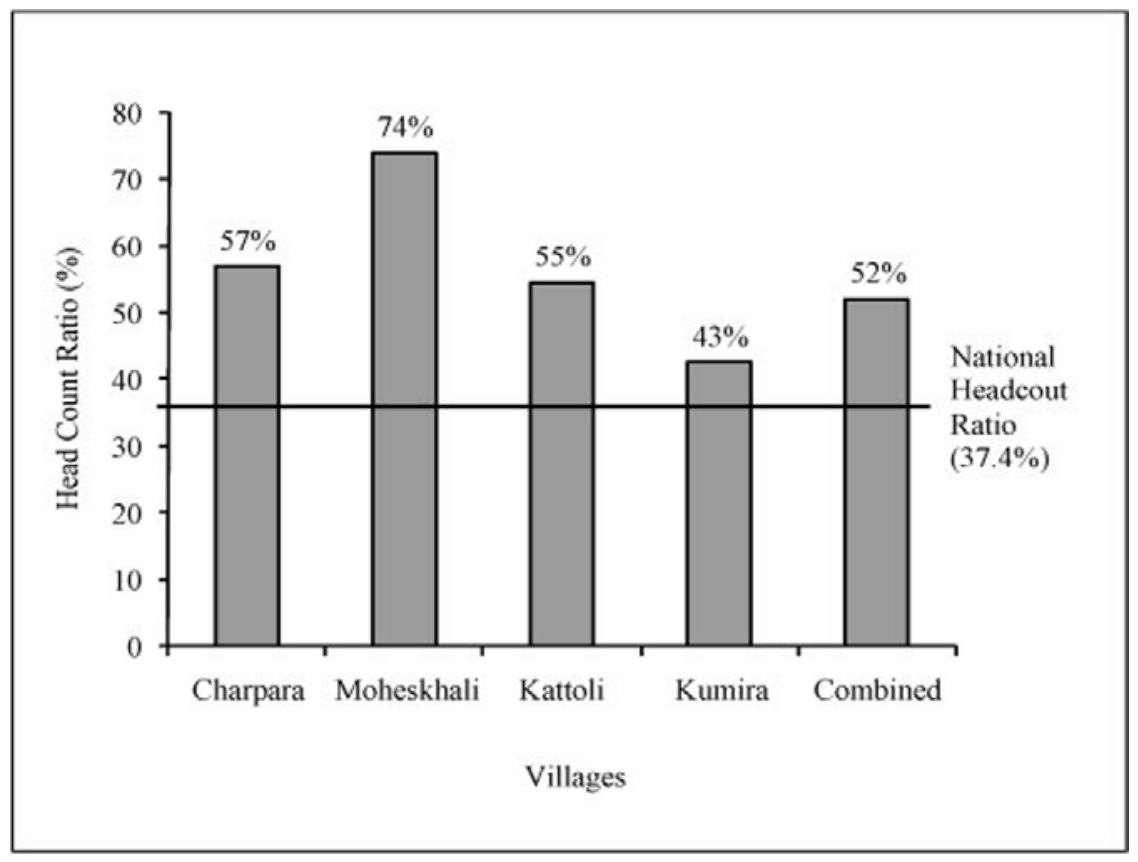

Figure 3. Headcount Ratio in the four investigated villages with national head count ratio. 


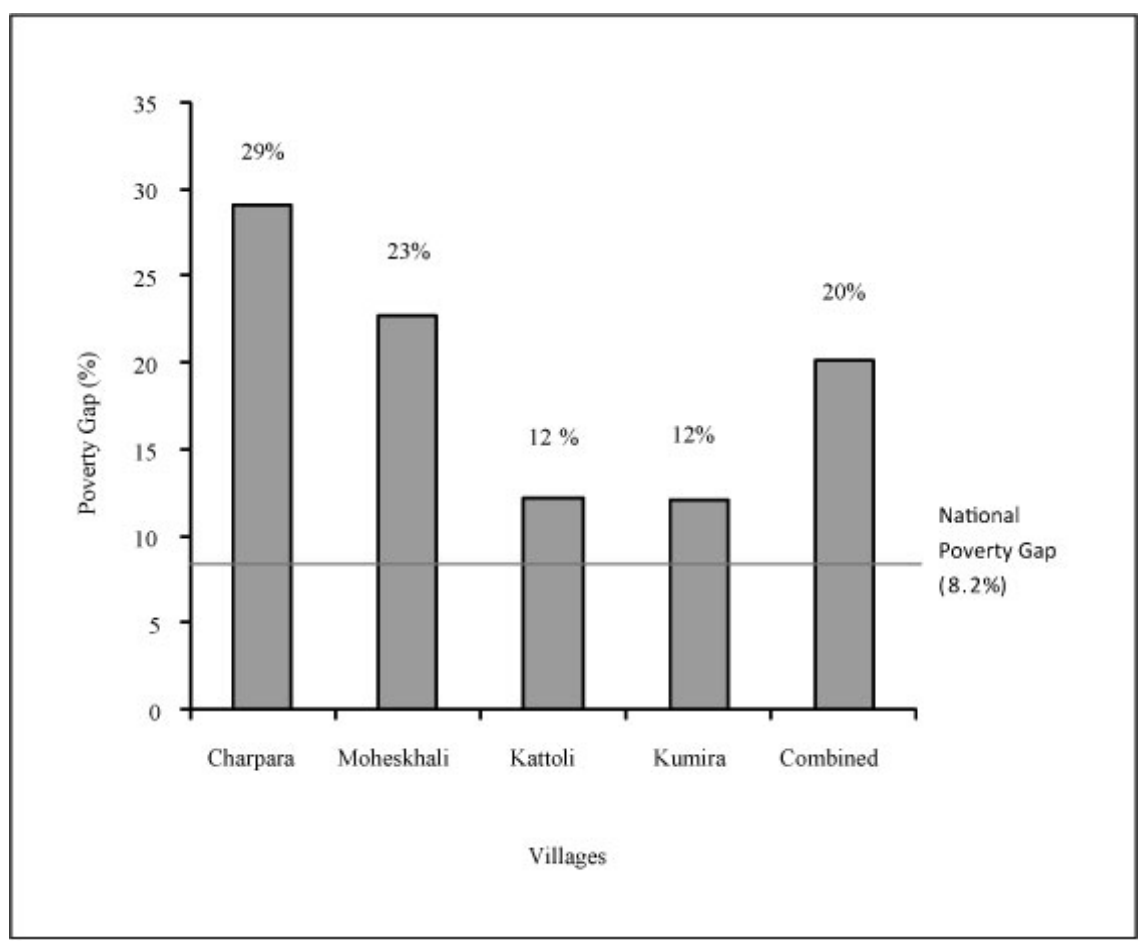

Figure 4. Poverty Gap in different investigated villages (the vertical straight line showing the national poverty gap).

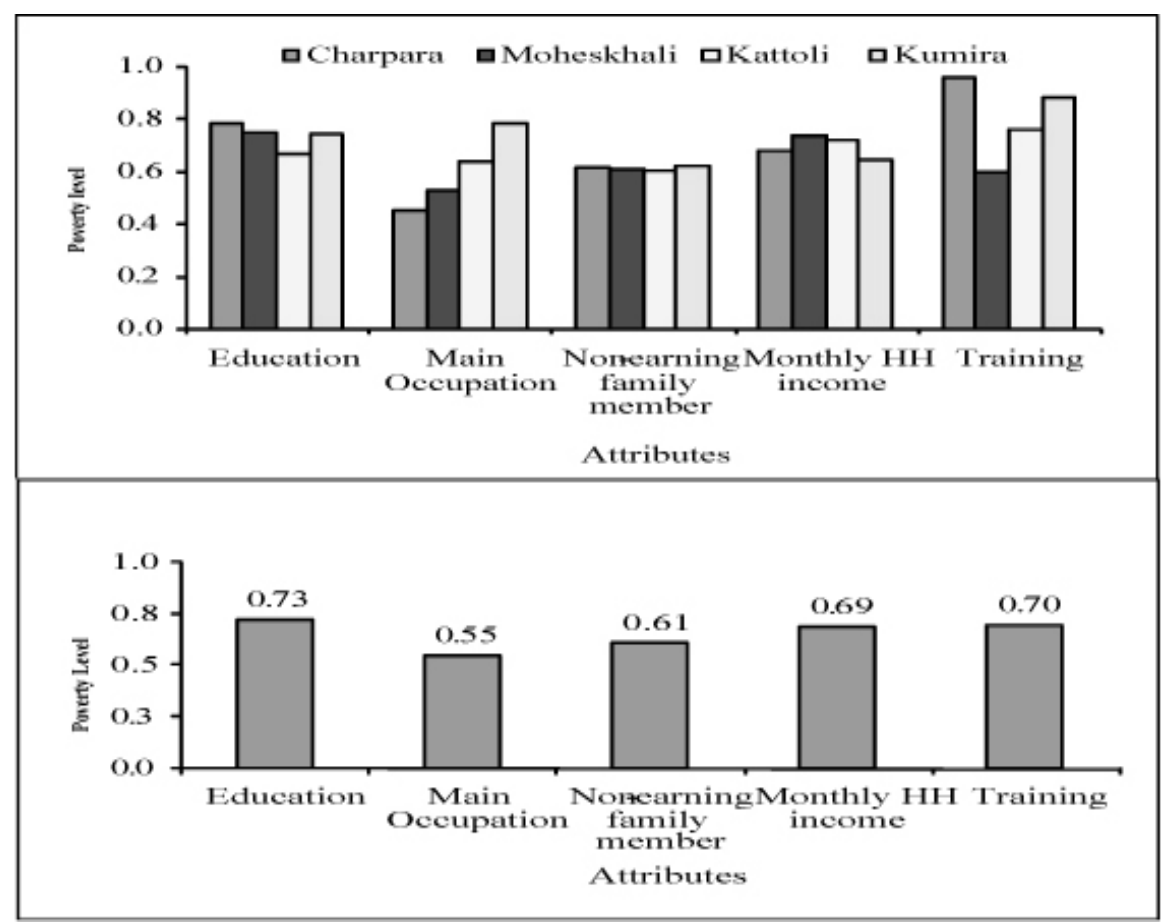

Figure 5. Human poverty level of different attributes, (a) separately in individual villages, (b) combined poverty indices of the four investigated villages. 


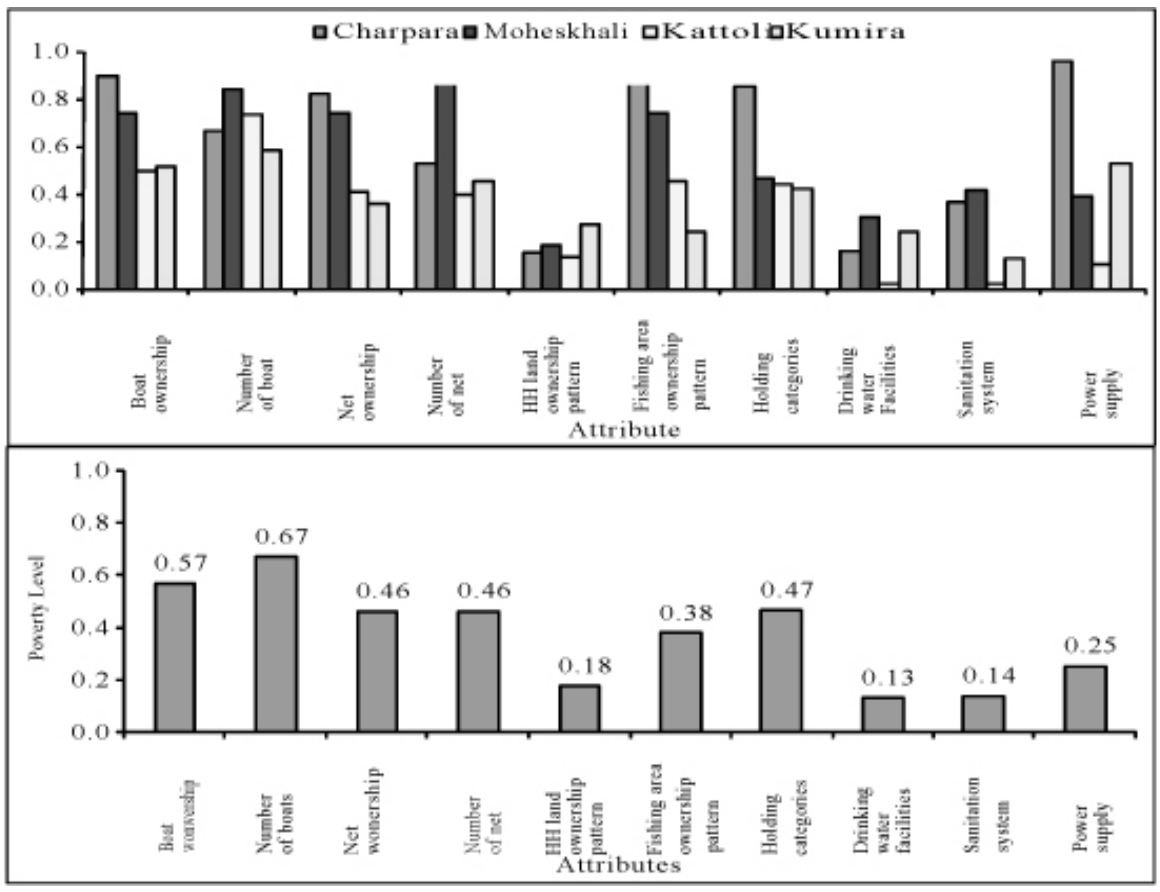

Figure 6. Physical poverty level of different attributes, (a) separately in individual villages, (b) combined poverty indices of the four investigated villages.

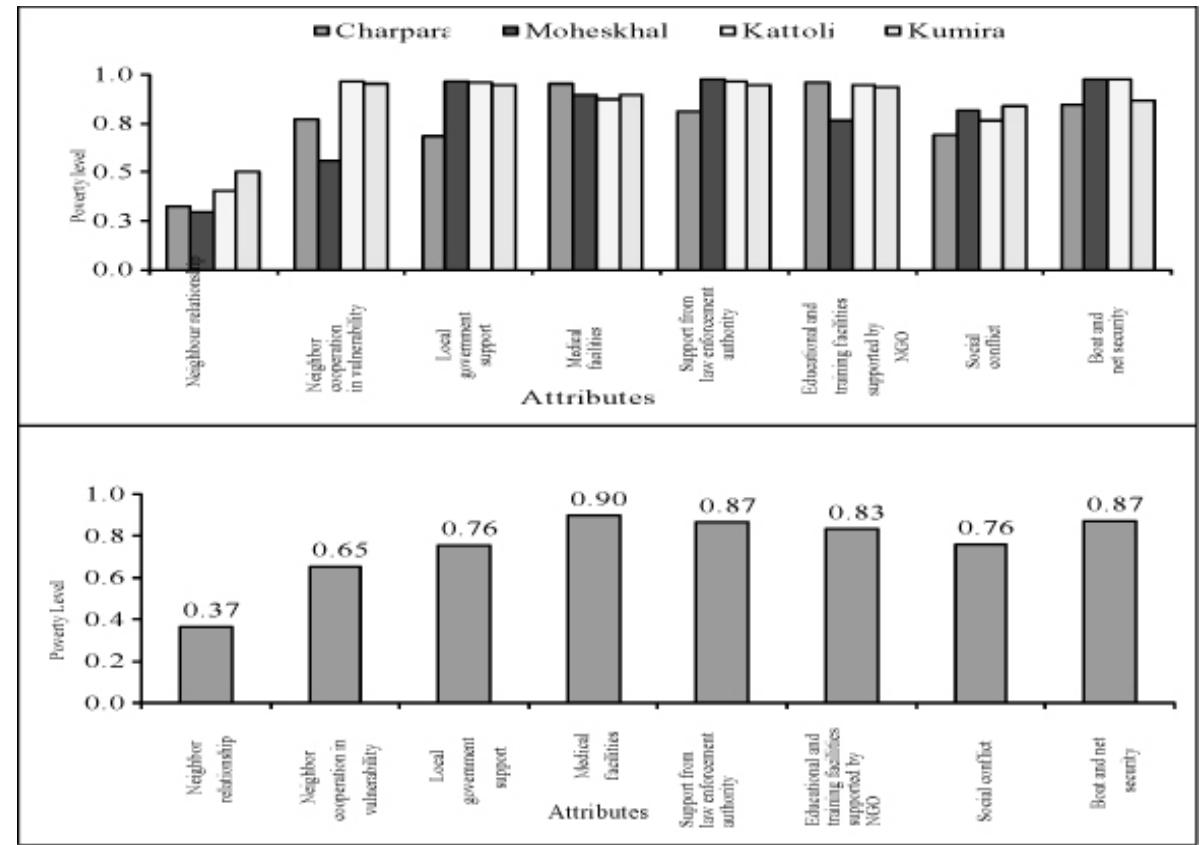

Figure 7. Social poverty level of different attributes, (a) separately in individual villages, (b) combined poverty indices of the four investigated villages. 


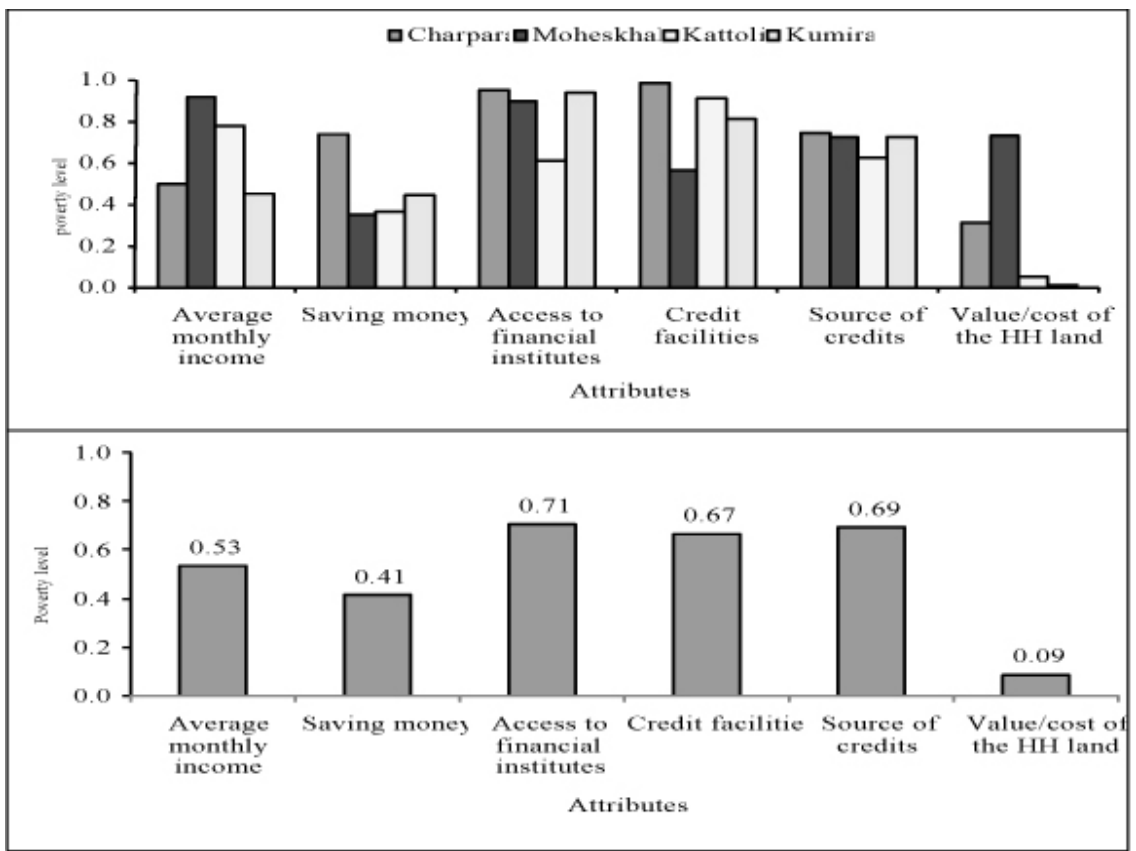

Figure 8. Financial poverty level of different attributes, (a) separately in individual villages, (b) combined poverty indices of the four investigated villages.

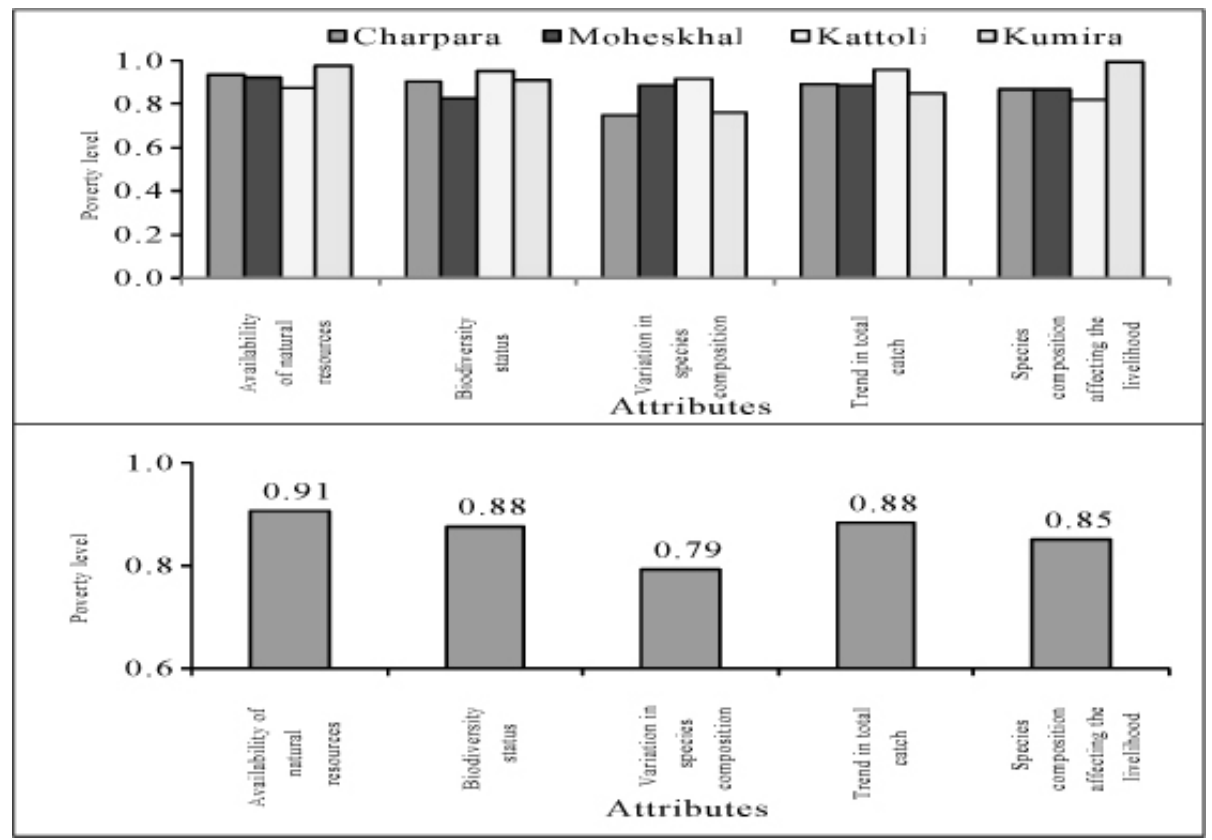

Figure 9. Natural poverty level of different attributes, (a) separately in individual villages, (b) combined poverty indices of the four investigated villages. 


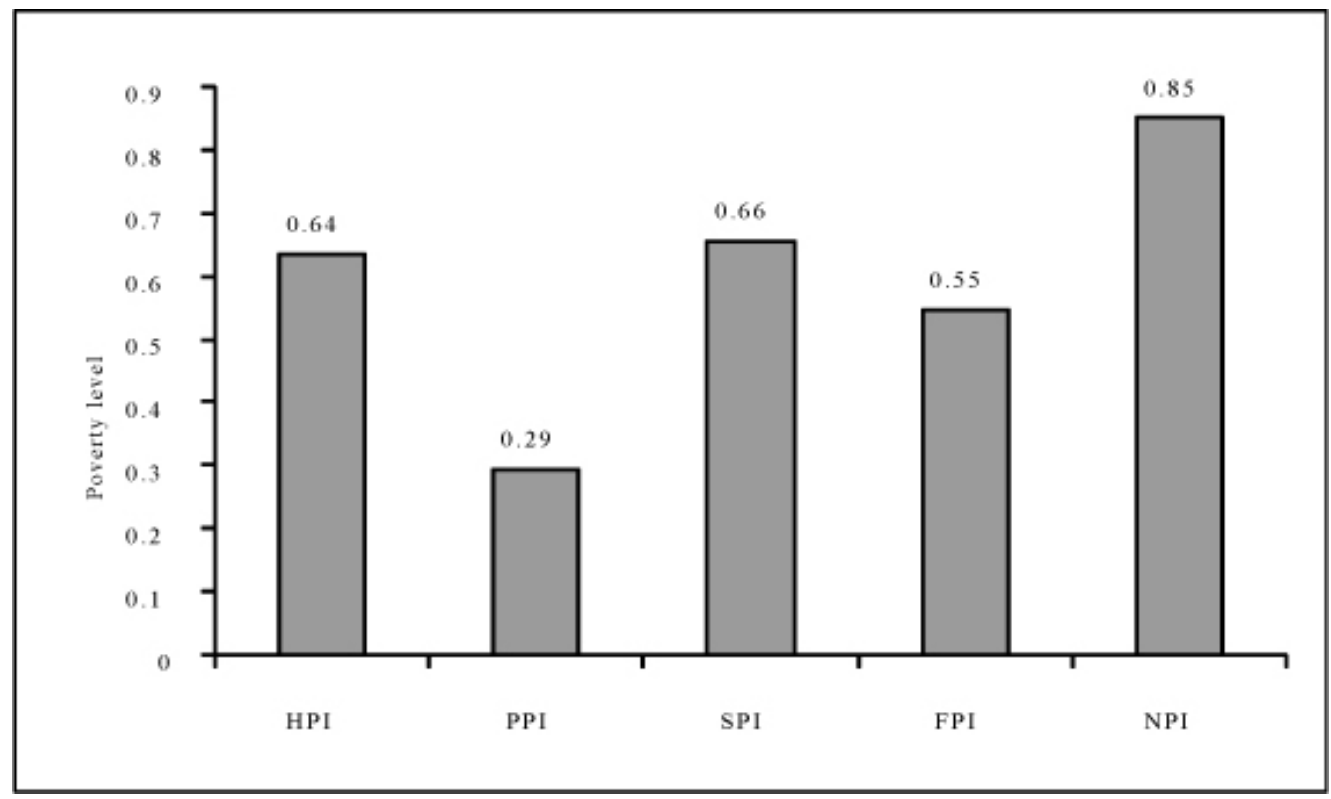

Figure 10. Asset-wise combined poverty level of ESBN fishermen in Bangladesh. 